\title{
Advances in Big Data Applications for transportation: airline, highway, and railway
}

\author{
Babak Daneshvar ROUYENDEGH ${ }^{1,2}$, Emine Nur NACAR ${ }^{1}$ \\ ${ }^{1}$ Ankara Yıldırım Beyazıt University, Turkey \\ 2Sultan Qaboos University, Oman
}

Received: 24.07.2020, Revised: 16.01.2021, Revised: 01.03.2021, Revised: 06.04.2021, Accepted: 06.04.2021

doi: http://dx.doi.org/10.29015/cerem.882

\begin{abstract}
:
Aim: The purpose of this article is to present the latest advances in big data applications in the industries of the transportation sector such as airline, highway, and railway. It is difficult to analyze data in transportation because there is continuous real-time data flow. Since the improvements made are fast with the same logic, it is necessary to catch up with the new developments. Data should be analyzed with the big data concept because data stacks highly contain non-structural data types in transportation data. Although the mentioned industries are complementary to each other, the applications differ depending on the needs of the industry. Thus, solutions to specific problems in different industries using big data applications should be addressed.
\end{abstract}

Design / Research methods: In accordance with the purpose of the study, big data studies that provide added value to the transportation sector were examined. Studies have been filtered through some criteria which are whether the application is adaptable to the industry, the study is available online in full-text, and its references are from respectable sources.

Conclusions / findings: All the big data application studies in the academy are not adaptable in reallife problems or suitable for all situations. For this reason, trying all of the applications will lead to moral and material losses for firms. This study is a guideline for companies to follow the developments in the big data concept and to choose the one that suits their problems. Thus, the gap between academia and industry was tried to close.

Originality / value of the article: Although studies are referring to big data applications in the transportation sector, this study differs from others in terms of specifically analyzing big data applications in different industries such as airline, highway, and railway in the transportation sector

Keywords: Big data, transportation, airline, highway, railway

JEL: C55, L9, L92, L93

\footnotetext{
1,2 Correspondence address: Babak Daneshvar Rouyendegh (Babek Erdebilli), Department of Industrial Engineering, Ankara Yıldırım Beyazıt University, Turkey \& Department of Mechanical and Industrial Engineering, Sultan Qaboos University, Oman e-mail: babek.erdebilli2015@gmail.com
} 


\section{Introduction}

Since the invention of computers, the computing technology curve has become steeper every year. Search algorithms have become more efficient and data is taking much less storage space. Accordingly, it is less arduous to retrieve data. As technology evolved, the size of the data grows rapidly. Thus, it became difficult to analyze and control the data. Especially after the development of the Internet of Things (IoT), the data grew exponentially that needed a way to analyse it to get useful information.

The big data concept came from the data with lots of rows that ordinary statistical methods are not sufficient enough to be analyzed. In the case of analysis, some Machine Learning (ML) and Artificial Neural Network (ANN) methods ease the job by fitting a model for the data. The difference is only the size of the data which needs more space to be stored by combining multiple computers to prepare enough space for the data.

In the case of time-series data, which is common in transportation system data, further methods are needed to catch the effective factors and the relationship between them. The data pre-processing phase, such as outliers and missing value issues, took a lot of time, and sectors are affected by this situation. On the other hand, data storage is another issue that should be taken into account. As a solution, the big data method has been used in almost every field, like medical, food, and textile industries and it started from developed countries to improve their services by taking useful information from the data. Due to the sensor system in almost every vehicle, the data size increases. Continuous monitoring of roads and highways will bring benefits to management only with secure handling and classification of largescale data. This is possible with the analysis of big data.

This study aims to provide a literature review of big data applications in the largest industries which are airline, highway, and railway from the transportation sector. For this purpose, by evaluating the literature research in the transportation sector, industry differences, and areas that can be improved within the same sector are revealed. Although the specified industries seem to be complementary to each other, there are great differences in terms of application. In this way, it was planned 
to provide researchers with information about the gaps in the sector and areas that could be improved.

Section 2 includes some introduction to the history of big data application and some similar methods. Then, the big data application will be explained in three transportation systems in section 3. There is no case study in this paper as the purpose of this study is to provide a literature review for the mentioned subjects.

\section{Big data}

It is stated that the first discourse about big data was used by Fremont Rider, a librarian at Wesleyan University. Rider predicted that the number of books in the library would double every sixteen years (Craver 2019). The term big data was coined by Charles Tilly in 1984 as “...the investigations tend to lose their wit, grace, and sense of proportion in the pursuit of statistical results, that none of the big questions has yielded to the bludgeoning of the big-data people..." (Tilly 1984). However, it is a matter of debate whether the use of the word big data in the mentioned study has the same meaning as today's use. American computer scientist Denning stated that a tool that can keep the pattern of data in memory can be invented: "Both auto-class and the genetic memory show that it is possible to build machines that can recognize or predict patterns in data without knowing the meaning of the patterns. Such machines may eventually be fast enough to deal with large data streams in real-time.” (Denning 1990). In 1997, two people working at MRJ Technology Solutions at NASA Ames Research Center stated in a conference paper that big data refers to large data sets that take up a lot of space in the computers' memory. Thus, the place of big data in the digital environment became clear (Cox, Ellsworth 1997).

Big data is a powerful concept to extract useful information from a large amount and variety of data. Big data has brought a new perspective to the world of data, as it has enabled us to process large amounts of data by removing some constraints and can also operate ML processes. The ML concept has been used from the last decade to make a model for the data based on the statistical methods and has also given 
some prediction based on the proposed model where there is some dependent variable which is called a supervised model. On the other hand, some unsupervised methods can be used as ML algorithms which has some common aspects with the big data, which came from data without any dependent variable in which the relationship between the variables and the clustering methods are applied. Similarly, the ANN tries to fit a model to a data set with some dependent variables by using extra hidden layers to make the perfection, which is used, in image processing, voice recognition, etc. The big data concept arises from a need which is the inability to process data using traditional methods. With the increase in the size of the data and the diversification of its type, difficulties have arisen in handling, storing, and processing the data. According to (Attoh-Okine 2015) there are 5 challenges in data: heterogeneity, inconsistency and incompleteness, privacy and data ownership, timelines, and merging data. This concept has made it possible to combine data from different types and sources. Multiple computers come together in big data and act as a single computer in both software and hardware. It allows to store and process data of different types and sizes such as text and video together in a single computer. This has opened up new horizons in the field of data analytics, and the performance of ML algorithms has increased as the computing power has increased. Big data has been a start for discoveries and has broadened our perspective on data science.

The features of big data are changing in different studies like described as $3 \mathrm{~V}$, $5 \mathrm{~V}$, and 7V. But $5 \mathrm{~V}$ is one of the most used (Attoh-Okine 2015; Nunez, AttohOkine 2015; Zhong et al. 2016). Data processing difficulties are related to the volume, variety, velocity, verification, and value of the data. Volume refers to the size of the data to be processed in a certain time frame. For example, there are thousands of sensors in autonomous vehicles. The faster the data in this sensor is processed, the more efficiency is obtained from the vehicle. Variety refers to the different types of data which are structured, semi-structured, and unstructured. Velocity is the speed of the data to be analyzed. It is necessary to be able to process the received data quickly. According to the verification, there may be meaningless records such as dirty data that contains duplicate, outdated, insecure, incomplete, inaccurate, and inconsistent data. These records need to be cleaned because they affect the data results. For example, the speed of an autonomous vehicle $-10 \mathrm{~km} / \mathrm{h}$ is 
an example of dirty data. The speed is expected to be at least $0 \mathrm{~km} / \mathrm{h}$. The data must provide added value to the company. Otherwise, there is no need to work on it because the data is not fit for the purpose. This is the value feature of big data. It is not necessary to have these features together. For example, data consisting of three types of variables, 1 billion observations and 1 million variables are also difficult to process. However, the combination of all features will make it even more difficult to process the data.

\section{Big data applications in transportation sector}

Due to the Global Positioning System (GPS) transceivers, Radio-frequency identification (RFID) tag readers, smart meters, and sensors used in the transportation sector, data are accumulating at an increasing rate. This collected data can be used to optimize operations and run organizational business intelligence.

Both public institutions and the private sector have to manage the big data caused by traffic problems, developing new regulations appropriate to the conditions, and optimizing transportation. Data inference can inform both shortterm and long- term investment decisions. It is possible to reach a lot of information from planning the transportation route to vehicle and driver behavior.

Intelligent Transportation Systems (ITS) is a subject that attracts great attention from researchers and practitioners in terms of effective use of capacity, increasing security, determining optimal routes. The purpose of ITS is due to the excess of big data and the fact that many issues are now more controllable. Because the more data on the subject, the closer the result is to reality. For this reason, big data seems to be a big problem, but in transportation, it is the biggest resource in analyzing the character of the system.

The airline, railway, and highway industries are among the most used in the transport industry. However, different applications are observed no matter how much they are in the same sector. For example, although vehicle routing problems seem to be common to all of them, there are minor differences. Although there is no concrete route in the airline, the boundaries of the countries are in question. On the 
highway, there are different applications for roads, tunnels, and bridges. Approaches related to the working principle of sensors are generally followed in railway and highway. Within the scope of big data, most studies have been produced in the airline industry.

This section consists of three parts which are about three different transportation systems. In each part, the application of big data is provided in terms of some examples.

\subsection{Big data applications in airline industry}

According to Boeing, a major development is expected in air traffic, including $4.6 \%$ traffic growth by 2038 (Boeing 2019). This indicates that the data will increase day by day and data traffic will become more concentrated. Airline carriers such as Ryanair, KLM, SWISS, Delta, and Turkish Airlines use big data for different purposes such as better service to the customer, and baggage tracking(Odarchenko et al. 2019). According to (Larsen 2013), optimizing airspace and system performance requires large-scale data due to its diversity. Flight information and data for radar tracking can be more than $30 \mathrm{~TB}$. With the addition of factors such as historical data and datasets, the data size can be up to $100 \mathrm{~TB}$. Working with such extensive data is not possible with traditional methods, but it can be realized with big data algorithms. On the other hand, the weather prediction and the air traffic should have a significant relationship which needs much more space to investigate their relationship where the weather data are time series huge. For this reason, some methods, algorithms, and applications have been developed for big data. The studies of big data in different fields were investigated mostly in the aviation industry.

Dinis et al. (2019) developed a big data and predictive analytics (BDPA) tool using Bayesian networks (BNs) to eliminate uncertainties in capacity planning. The data required for this method, which is used in aircraft Maintenance, Repair, and Overhaul (MRO) organizations, received as real maintenance data from 372 aircraft of Portuguese MRO. They have created 3 BNs for the BDPA tool and have made their verification with Mean Absolute Deviation (MAD), one of the common forecasting methods. (Hausladen, Schosser 2020) developed a maturity model for the airline network planning challenges resulting from big data. In the case study of 
nine airlines, four business models according to full-service carriers, low-cost airlines, scheduled charter airlines, and cargo airlines were developed. It is concluded that full-service carriers and cargo airlines are more mature than others.

Overbooking is still an issue that has not been fully resolved in aviation. Since the aviation industry is a very costly sector, even one passenger makes money for the company. Since it is a frequent problem that passengers do not come to flight, companies can book many passengers for one seat. If more than one person arrives for the same seat, the person will wait for the next flight. This situation affects the reputation of the company negatively and causes the loss of customers. To prevent the overbooking crisis, Ma et al. (2019) looked at the big data from another angle which is social media outcomes. For this reason, they used United Airlines' Twitter data for 2017. Thus, they analyzed traditional yield management by using the advantages of big data. In another study, the passenger value model was proposed by using social media data. In the article, which aims to improve Customer Relationship Management (CRM), the idea is to analyze the social media value and behavior information of the passengers by using the example of China Southern Airlines on Sina Weibo. Passengers' criticism on social media will also affect other customers. Increasing the transfer of information from social media will improve the company's customer relations (Chen et al. 2016).

In the aviation industry with large fuel costs, optimizing airline routes is an important factor for profitability because airline routes create both cost and time problems. Solving the problem with big data is one of the best approaches when the subject is so important, and the data is large scale. For this, Kasturi et al. (2016) have optimized the airline routes by using big data analysis with heuristic approaches. There are some situations to be considered in this regard. For example, it is not possible to prepare a specific route for the aviation industry. Because conditions such as weather, landing permits, runway status, and airplane features affect the route.

Demand imbalances are one of the biggest obstacles to the firms' ability to invest forward. Irregular demands will affect the company both financially and morally. For this, companies make demand forecasts on a short and long term. While short-term demand forecasts are mostly related to the current situation of the 
company and emergencies, long-term demand forecasts are mostly related to strategic decisions and investments. In the aviation industry, where there are many emergencies, Kim and Shin (2016) worked on the air passenger demand forecast from short-term forecasts. The proposed prediction model gives an average of 5.3\% error.

\subsection{Big data applications in highway industry}

Highway industry consisted of three phases: Roads, tunnels and bridges to provide safety for both human and goods. Sensors are often used to analyze data in road transport. Sensors record a significant amount of data, but it is often not possible to use this data except in special cases. Big data analytics provides an algorithm for tracking these data sets. It also gives predictable results for unexpected events such as in large sensor systems (Mital et al. 2015). Analyzing a sensor consists of data energy efficient clustering, data gathering, data analysis, energy efficiency, and data storage (Boubiche et al. 2018). Based on a study for the use of big data in road safety by Styliano et al. (2019), in-situ sensors, remote sensors, cameras, microphones, wireless sensor networks, and mobile devices are the important sources for the data which are constantly gathered. Similarly, another study suggested the big data application in the road transport by Cambos-Cordobes (2018), the Internet of Things trend provides a chance for the deployment of the Connected Vehicle (Car-as-a-sensor) concept, supported by advanced V2X communications, making a massive data volume that should be analyzed under big data concept. According to the Bureau of Transportation Statistics, seasonally adjusted vehicle miles traveled (VMT) was 242.260 million in January 2010 and 274.164 million in December 2019 (Traffic Volumes and Trends 2019). This corresponds to an approximately $13 \%$ increase in 10 years.

Secondly, for the tunnel phase, the morphological characteristics of structural defects such as lining cracking, water seepage, and insufficient thickness, and its relationship with the tunnel space position and geological conditions are some important characters of the tunnel (Ding 2019) in which the big data becomes a useful method to defect the structure and traffic accident. In another study by Pan (2019), the important factors in the tunnels have been identified and some kind of 
big data techniques were implemented to analyze the data. The author believes that these methods will be helpful economically and improve the management of the tunnels.

Finally, in terms of the bridges, big data is used to investigate serviceability for the aged bridge according to Liang et al. (2016). In this study, apart from big data, deep learning methods have been implemented to evaluate the bridge serviceability according to real-time sensory data or achieved bridge-related data. Another study was done by Wang (2018) as an evaluation of highway bridges in the United States based on four regions is compared. The data matrix has more than a million bridges represented in a row. For this purpose, some statistical methods were applied to construct a comparison between the properties of the bridges in the different four zones.

\subsection{Big data applications in the railway industry}

Usage areas and benefits of big data on the railway attracted the attention of researchers and engineers interested in the field (Ghofrani et al. 2018). However, there is still not much work on the subject.

The railway is one of the industries that need big data solutions because of railway infrastructure and maintenance. Due to difficulties such as the amount of data, heterogeneous sources of information, real time requirements, algorithms to predict wearing, and huge business opportunities, problems cannot be solved with old methods and some technological methods are needed (Thaduri et al. 2015). It is also possible to solve problems involving big data with optimization techniques such as neural networks and k-means, or metaheuristic approaches (Nunez, Attoh-Okine 2015).

Fumeo, Oneto and Anguita (2015) worked on condition-based maintenance (CBM) to maximize the remaining life of the train axle bearings. Analyzing data from a large number of sensors is a major challenge because the data comes from different sources and in large numbers in real-time ( $\mathrm{Li}$ et al. 2013). Therefore, Fumeo, Oneta, and Anguita proposed a CBM based on SDA (Streaming Data Analysis) algorithm that utilizes online Support Vector Regression (OL-SVR) using 
real-life data. They stated that collecting and analyzing data with this method will optimize the lifetime.

Railway failures can cause not only technical costs but also some customerrelated costs and reliability issues related to passenger safety. Image processing approach is used with the recordings obtained from video cameras using data visualization. In this way, the railway failure was estimated. It was emphasized that action should be taken at the right place and the right time to prevent unexpected results (Jamshidi et al. 2017).

The train delay systems currently used cannot catch up with today's technologies. However, it is possible to estimate these delays with some error rates by using historical data. However, the analyzability of the data is very difficult due to the data type and number. Therefore, big data methods are needed. For this reason, Oneto et al. (2018) analyzed until the last data by using a fast learning algorithm for Shallow and Deep Extreme Learning Machines. The algorithm has been compared with the methods used today. It has been observed that the proposed algorithm gives better results compared to the current method according to the Italian rail networks. This has been confirmed by the actual data provided by Rete Ferroviaria Italiana (RFI), which has been shown to yield twice as good as the current methods.

It is possible to use big data on marketing decisions in the rail industry. In a study by Zhang and Gong (2014), marketing decision-making using this data is explained. Thus, it has been seen that big data not only provides benefits in technical matters but also plays a role in strategic decisions that will support the growth of the company. Another study by (Núñez et al. 2014) discusses the applicability of big data to facilitate maintenance decisions regarding railway lines. Railway track monitoring data reach enormous dimensions within minutes. However, the data are not yet fully used due to the lack of suitable techniques. Therefore, valuable information is contained in large amounts of memory from different sensors.

Table 1 summarizes the mentioned transportation system studies in the article. These studies, which are examined as airline, highway and railway, are grouped under three sub-headings in the highway sector: bridges, tunnels and roads. In the 
table, it is visually expressed that big data applications are carried out in different areas by giving the title of the articles and the topics covered.

Table 1. The list of some applications of big data in transportation system

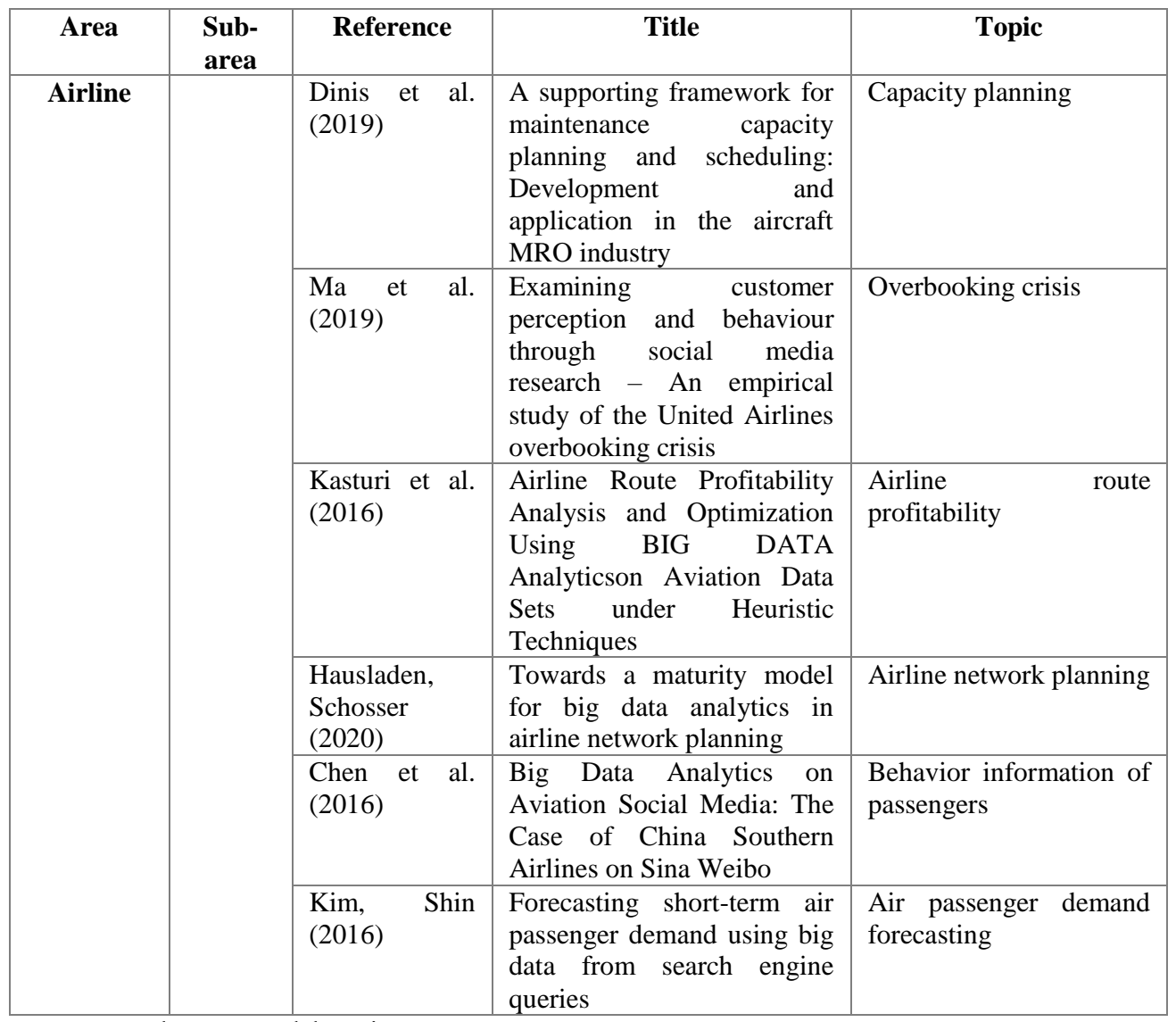

Source: Authors' own elaboration. 
Table 1. Cont. ...

\begin{tabular}{|c|c|c|c|c|}
\hline \multirow[t]{6}{*}{ Highway } & \multirow[t]{2}{*}{ Roads } & $\begin{array}{l}\text { Styliano et al. } \\
\text { (2019) }\end{array}$ & $\begin{array}{l}\text { Mobility Patterns, Big data } \\
\text { and Transport Analytics: } \\
\text { Tools and applications for } \\
\text { modeling }\end{array}$ & Sensor data management \\
\hline & & $\begin{array}{l}\text { Cambos- } \\
\text { Cordobes } \\
(2018)\end{array}$ & $\begin{array}{l}\text { Big data in road transport } \\
\text { and mobility research. } \\
\text { In Intelligent Vehicles }\end{array}$ & $\begin{array}{l}\text { Geolocation ,operational } \\
\text { mobile phone data, and } \\
\text { social network } \\
\text { crowdsourced } \\
\text { information management }\end{array}$ \\
\hline & \multirow[t]{2}{*}{ Tunnels } & Ding (2019) & $\begin{array}{l}\text { Big Data Analysis of } \\
\text { Structural Defects and } \\
\text { Traffic Accidents in Existing } \\
\text { Highway Tunnels }\end{array}$ & $\begin{array}{l}\text { Structural Defect and } \\
\text { traffic accident }\end{array}$ \\
\hline & & Pan (2019) & $\begin{array}{l}\text { Design of Integrated } \\
\text { Management and Control } \\
\text { System for Mechanical and } \\
\text { Electrical Equipment of } \\
\text { New Generation Highway } \\
\text { (Road) Tunnel }\end{array}$ & $\begin{array}{l}\text { Cleaning and analysis of } \\
\text { the historical } \\
\text { maintenance data of } \\
\text { mechanical and } \\
\text { electrical equipment }\end{array}$ \\
\hline & \multirow[t]{2}{*}{ Bridges } & Liang (2016) & $\begin{array}{l}\text { Big data-enabled multiscale } \\
\text { serviceability analysis for } \\
\text { aging bridges }\end{array}$ & $\begin{array}{ll}\text { Deep } & \text { learning } \\
\text { techniques } & \end{array}$ \\
\hline & & Wang (2018) & $\begin{array}{l}\text { Big data for the urban } \\
\text { sustainability }\end{array}$ & $\begin{array}{l}\text { Bridges } \quad \text { properties } \\
\text { comparison between } \\
\text { four regions in US }\end{array}$ \\
\hline \multirow[t]{5}{*}{ Railway } & & $\begin{array}{l}\text { Núñez et al. } \\
\text { (2014) }\end{array}$ & $\begin{array}{l}\text { Facilitating maintenance } \\
\text { decisions on the Dutch } \\
\text { railways using big data: The } \\
\text { ABA case study }\end{array}$ & Maintenance decisions \\
\hline & & $\begin{array}{l}\text { Zhang, Gong } \\
\text { (2014) }\end{array}$ & $\begin{array}{l}\text { Application of big data } \\
\text { technology in marketing } \\
\text { decisions for railway freight }\end{array}$ & Marketing decisions \\
\hline & & $\begin{array}{l}\text { Fumeo et al. } \\
\text { (2015) }\end{array}$ & $\begin{array}{l}\text { Condition based } \\
\text { maintenance in railway } \\
\text { transportation systems based } \\
\text { on big data streaming } \\
\text { analysis }\end{array}$ & $\begin{array}{l}\text { Maximizing } \\
\text { remaining life of the } \\
\text { train axle bearings }\end{array}$ \\
\hline & & $\begin{array}{l}\text { Jamshidi et al. } \\
\text { (2017) }\end{array}$ & $\begin{array}{l}\text { A Big Data Analysis } \\
\text { Approach for Rail Failure } \\
\text { Risk Assessment }\end{array}$ & Railway failures \\
\hline & & $\begin{array}{l}\text { Oneto et al. } \\
(2018)\end{array}$ & $\begin{array}{l}\text { Train Delay } \\
\text { Systems: A Big Dation } \\
\text { Analytics Perspective }\end{array}$ & Train delay systems \\
\hline
\end{tabular}

Source: Authors' own elaboration. 
When the studies were examined, we observed that route planning was made for all three industries. Studies on sensors have been mostly carried out in the highway and railway industries. In addition, topics such as marketing, maintenance, customer relations, delay problems and accidents are covered. Since these issues, which are a problem in the transportation sector, cannot be dealt with due to the size of the data, an attempt was made to solve these problems using big data applications which is the sub-branch of artificial intelligence. In order to show that big data studies can be done in many fields, articles on different subjects are included. Although there has not been much work done so far, the large area to work will shed light on other studies that can be done in the transportation sector regarding big data.

\section{Conclusion}

This study aimed to investigate the application of big data methods in the inference of transportation systems' data in three different sectors. In this way, a general view is provided for the researchers to catch up with big data applications in the field of the transportation sector. As a result, the methods which can be useful in the corresponding industries may be analyzed. By data revolution, the need for the methods to handle the data gathered from different sectors increases the demand for big data analysis, that is why some other mathematical, numerical, and statistical methods are used for this purpose. Especially, with the invention of the sensor systems in almost every vehicle, the size of the data grows exponentially in the transportation industry. Although the history of the big data concept backs on less than a decade, its application is used frequently, especially in the past three years that verifies the importance of big data. This study provides a literature review for some big data applications in three different transportation industries as well as some examples of the huge size of the data. The role of big data was highlighted in different fields via diverse views, but that was not all. It is obvious that there is a lot of work and methods that have been done by big data that are not available in academic studies while they have been used frequently and accurately. 
So, there are other fields and other application methods in the mentioned three sectors that are not considered in this study. Therefore, as a future study, we plan to investigate the application of other methodologies such as ML and ANN in other transportation industries like maritime.

\section{References}

Attoh-Okine N. (2015), Big data challenges in railway engineering, in: Proceedings - 2014 IEEE International Conference on Big Data, doi: 10.1109/BigData.2014.7004424, pp. 7-9.

Boubiche S., Boubiche D.E., Bilami A., Toral-Cruz H. (2018), Big data challenges and data aggregation strategies in wireless sensor networks, IEEE Access, https://etarjome.com/storage/panel/fileuploads/2019-01-29/1548750575_E10512-e-tarjome.pdf [09.06.2021].

Campos-Cordobés S., Del Ser J., Laña I., Olabarrieta I.I., Sánchez-Cubillo J., Sánchez-Medina J.J., Torre-Bastida A.I. (2018), Big data in road transport and mobility research, in: Ingelligent vehicles. Enabling technologies and future developments, Jiménez F. (ed.), Butterworth-Heinemann, Madrid, pp. 175-205.

Chen S., Huang Y., Huang W. (2016), Big data analytics on aviation social media. The case of China Southern Airlines on Sina Weibo, Proceedings - 2016 IEEE 2nd International Conference on Big Data Computing Service and Applications, doi: 10.1109/BigDataService.2016.51, pp. 152-155.

Cox M., Ellsworth D. (1997), Application-controlled demand paging for out-of-core visualization, in: Proceedings of the IEEE Visualization Conference, doi: 10.1109/visual.1997.663888, pp. 1-11.

Craver K.W. (2019), School libraries in a time of change. How to survive and thrive, Libraries Unlimited, Santa Barbara.

Denning P. (1990), The science of computing: saving all the bits, “American Scientist”, vol. 78 no. 5 , pp. 402-405.

Ding H., Liu S., Cai S., Xia Y. (2019), Big data analysis of structural defects and traffic accidents in existing highway tunnels, in: International Conference on Information Technology in Geo-Engineering, Springer, Cham, pp. 189-195.

Dinis D., Barbosa-Póvoa A., Teixeira Â.P. (2019), A supporting framework for maintenance capacity planning and scheduling. Development and application in the aircraft MRO industry, "International Journal of Production Economics", vol. 218, pp. 1-15.

Fumeo E., Oneto L., Anguita D. (2015), Condition based maintenance in railway transportation systems based on big data streaming analysis, "Procedia Computer Science", vol. 53 no. 1, pp. 437446.

Ghofrani F. et al. (2018), Recent applications of big data analytics in railway transportation systems: a survey, "Transportation Research Part C: Emerging Technologies", vol. 90, pp. 226-246. 


\section{ADVANCES İN BIG DATA APPLICATIONS FOR TRANSPORTATION ...}

Hausladen I., Schosser M. (2020), Towards a maturity model for big data analytics in airline network planning, "Journal of Air Transport Management", vol. 82, p. 101721.

Jamshidi A., Faghih-Roohi S., Hajizadeh S., Núñez A., Babuska R., Dollevoet R., Li Z., De Schutter B. (2017), A big data analysis approach for rail failure risk assessment, "Risk Analysis", vol. 37 no. 8, pp. 1495-1507.

Kasturi E., Prasanna Devi S., Vinu Kiran S., Manivannan S. (2016), Airline route profitability analysis and optimization using big data analyticson aviation data sets under heuristic techniques, "Procedia Computer Science", vol. 87, pp. 86-92.

Kim S., Shin D.H. (2016), Forecasting short-term air passenger demand using big data from search engine queries, "Automation in Construction", vol. 70, pp. 98-108.

Li H., Quian B., Parikh D., Hampapur A. (2013), Alarm prediction in large-scale sensor networks. A case study in railroad, in: Proceedings - 2013 IEEE International Conference on Big Data, doi: 10.1109/BigData.2013.6691771, pp. 7-14.

Liang Y., Wu D., Liu G., Li Y., Gao C., Ma Z.J., Wu W. (2016), Big data-enabled multiscale serviceability analysis for aging bridges, "Digital Communications and Networks", vol. 2 no. 3, pp. 97107.

Ma J., Tse M., Wang X., Zhang M. (2019), Examining customer perception and behaviour through social media research. An empirical study of the United Airlines overbooking crisis, "Transportation Research Part E: Logistics and Transportation Review", vol. 127, pp. 192-205.

Mital R., Coughlin J., Canaday M. (2015), Using big data technologies and analytics to predict sensor anomalies, in: Proceedings of the advanced Maui Optical and Space Surveillance Technologies Conference, Ryan S. (ed.), The Maui Economic Development Board, Maui.

Núñez A., Hendriks J., Li Z., De Schutter B., Dollevoet R. (2014), Facilitating maintenance decisions on the Dutch railways using big data. The ABA case study, in: Proceedings - 2014 IEEE International Conference on Big Data, IEEE, Washington D.C., pp. 48-53.

Nunez S.G., Attoh-Okine N. (2015), Metaheuristics in big data. An approach to railway engineering, in: Proceedings - 2014 IEEE International Conference on Big Data, doi: 10.1109/BigData.2014.7004430, pp. 42-47.

Odarchenko R., Hassan Z., Zaman A. (2019), Use of big data in aviation, in: Automated systems in the aviation and aerospace industries, doi: 10.4018/978-1-5225-7709-6.ch017, pp. 436-452.

Oneto L., Fumeo E., Clerico G., Canepa R. (2018), Train delay prediction systems. A big data analytics perspective, "Big Data Research", vol. 11, pp. 54-64.

Pan L.I.U., Bo D. (2019), Design of integrated management and control system for mechanical and electrical equipment of new generation highway (road) tunnel, "Tunnel Construction", vol. 39 no. S1, pp. 478-485.

Stylianou K., Dimitriou L., Abdel-Aty M. (2019), Big data and road safety. A comprehensive review, in: Mobility patterns, big data and transport analytics, doi: 10.1016/B978-0-12-812970-8.00012-9, pp. 297-343. 
Thaduri A., Galar D., Kumar U. (2015), Railway assets. A potential domain for big data analytics, "Procedia Computer Science", vol. 53 no. 1, pp. 457-467.

Tilly C. (1984), The Old Social History and the New Social Sciences, Research Foundation of State University of New York, 7(3), pp. 363-406.

Traffic Volumes and Trends (2019), U.S. Department of Transportation, Bureau of Transportation Statistics (BTS) calculation from U.S. Department of Transportation, Federal Highways Administration, Traffic Volumes and Trends, http://www.fhwa.dot.gov/policyinformation/travel_monitoring/tvt.cfm [29.05.2020].

Wang S.J., Moriarty P. (2018), Big data for urban sustainability, Springer Nature.

Zhang X., Gong D. (2014), Application of big data technology in marketing decisions for railway freight, in: International Conference of Logistics Engineering and Management, Shanghai, pp. 11361141.

Zhong R.Y., Newman S.T., Huang G.Q., Lan S. (2016), Big data for supply chain management in the service and manufacturing sectors. Challenges, opportunities, and future perspectives, "Computers and Industrial Engineering", vol. 101, pp. 572-591. 